\title{
Sources, occurrence and predicted aquatic impact of legacy and contemporary pesticides in streams
}

McKnight, Ursula S.; Rasmussen, Jes J.; Kronvang, Brian; Binning, Philip John; Bjerg, Poul Løgstrup

Published in:

Environmental Pollution

Link to article, DOI:

10.1016/j.envpol.2015.02.015

Publication date:

2015

Document Version

Peer reviewed version

Link back to DTU Orbit

Citation (APA):

McKnight, U.S., Rasmussen, J. J., Kronvang, B., Binning, P. J., \& Bjerg, P. L. (2015). Sources, occurrence and predicted aquatic impact of legacy and contemporary pesticides in streams. Environmental Pollution, 200, 64-76. https://doi.org/10.1016/j.envpol.2015.02.015

\section{General rights}

Copyright and moral rights for the publications made accessible in the public portal are retained by the authors and/or other copyright owners and it is a condition of accessing publications that users recognise and abide by the legal requirements associated with these rights.

- Users may download and print one copy of any publication from the public portal for the purpose of private study or research.

- You may not further distribute the material or use it for any profit-making activity or commercial gain

- You may freely distribute the URL identifying the publication in the public portal 


\section{Sources, occurrence and predicted aquatic impact of legacy and contemporary}

\section{2 pesticides in streams}

3

4 Ursula S. McKnight ${ }^{a, *}$, Jes J. Rasmussen ${ }^{b}$, Brian Kronvang ${ }^{b}$, Philip J. Binning ${ }^{a}$, Poul L. Bjerg ${ }^{a}$ 6 Denmark

\footnotetext{
$7 \quad{ }^{b}$ Department of Bioscience, Aarhus University, Vejlsoevej 25, 8600 Silkeborg, Denmark

${ }^{a}$ Department of Environmental Engineering, Technical University of Denmark, Miljoevej Building 113, 2800 Kgs. Lyngby,

*Corresponding author: Tel.: +45 4525 1412; Fax: +45 4593 2850; E-mail: usmk@env.dtu.dk; Co-authors email:

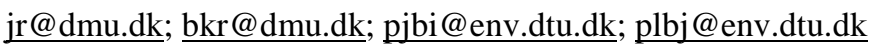

\section{ABSTRACT}

2 We couple current findings of pesticides in surface and groundwater to the history of pesticide usage, focusing on the potential contribution of legacy pesticides to the predicted ecotoxicological impact on benthic macroinvertebrates in headwater streams. Results suggest that groundwater, in addition to precipitation and surface runoff, is an important source of pesticides (particularly legacy herbicides) entering surface water. In addition to current-use active ingredients, legacy pesticides, metabolites and impurities are important for explaining the estimated total toxicity attributable to pesticides. Sedimentbound insecticides were identified as the primary source for predicted ecotoxicity. Our results support recent studies indicating that highly sorbing chemicals contribute and even drive impacts on aquatic ecosystems. They further indicate that groundwater contaminated by legacy and contemporary pesticides may impact adjoining streams. Stream observations of soluble and sediment-bound pesticides are valuable for understanding the long-term fate of pesticides in aquifers, and should be included in stream monitoring programs.

Capsule: Legacy pesticides, particularly sediment-bound insecticides were identified as the primary source for predicted ecotoxicity impacting benthic macroinvertebrates in headwater streams. 
26 Keywords: legacy pesticides; groundwater-surface water interaction; sediment-bound residues; benthic 27 macroinvertebrates; ecotoxicity; aquatic systems

\section{1. Introduction}

More than 85,000 chemicals are in production and use worldwide, with more than 2,200 produced in amounts exceeding 450 tons per year. Pesticides are second only to fertilizers in the amount of chemicals applied and extent of use in the environment (Stokstad and Grullon, 2013), with an estimated 1 to 2.5 million tons of active ingredients used each year, predominantly in agriculture (Fenner et al., 2013). Nearly 20,000 pesticide products have entered the market since registration began in 1947 (Lyandres, 2012) and more than 1,000 are sold annually in Denmark (Danish EPA, 2011).

The term pesticide covers a wide range of compounds that are typically broadly categorized on the basis of their pesticidal actions, including herbicides, fungicides, insecticides, nematicides, plant growth regulators, and others, or they can be classified on the basis of their general chemical nature (e.g. organochlorines; organophosphates) or mode of action (Arias-Estévez et al., 2008; Nollet and Rathore, 2010). Despite their recognized importance, especially for agricultural production and pathogen control, pesticides are now considered among the most harmful types of compounds impacting surface waters (Schwarzenbach et al., 2006). In particular, insecticides have been thought to be one of the principal stressors affecting stream macroinvertebrates, as well as fundamental ecosystem functions such as leaf litter decomposition (Peters et al., 2013; Schaefer et al., 2012).

The environmental consequences associated with land use intensification are considered one of the main drivers for increased biodiversity loss and impairment of ecosystem functions (Beketov et al., 2013), and ways to balance the need to feed the world without disastrous effects on soil, water and habitat are still being sought after. Pesticides are now widely recognized as prevalent (Konstantinou et al., 2006), including many of their metabolites (Barth et al., 2007) and production impurities (Holt et al., 2010; Reitzel et al., 2004) - which are typically not considered in ecotoxicological studies - and consistently detected over time (e.g. corn herbicides in Vecchia et al., 2009). The occurrence of pesticides is well-documented for specific environmental compartments, such as in soils (Olsen et al., 2011) and streambed sediment (Kronvang et al., 2003), groundwater and surface water (Gilliom, 2007; Roy and Bickerton, 2012), or rainwater (i.e. atmosphere) (Vogel et al., 2008). 
More recently, studies have begun to focus on the transport and ultimate fate of these compounds as they move through the different media, for example from agricultural application to soils (cropland) into the atmosphere (Asman et al., 2005) or into groundwater (Arias-Estévez et al., 2008), from groundwater to drinking water supply wells (Levi et al., 2014) or groundwater-dependent ecosystems (Ejrnaes et al., 2014), and then considering the ecotoxicological impacts once these compounds are present in surface water (Schaefer et al., 2013). Although studies exist that focus on linking pesticide transport from groundwater to surface water (e.g. Squillace et al., 1993; Kolpin et al., 2001), studies which endeavor to disentangle the contributions and importance of this entry pathway for aquatic ecosystems relative to the contribution of other routes, such as pesticide runoff from agricultural land, are still needed.

Moreover, it has become clear that a proper ecotoxicological understanding of the history of lowdose contamination, impacting stream environments over successive generations, is lacking (Artigas et al., 2012). This is due in part to the fact that pesticides are specifically designed for topsoil conditions and subsequently tested under controlled settings that do not accurately reflect the long history of pesticide exposure. This has contributed to the established viewpoint that contamination of surface waters by pesticide residues is transitory (occurring primarily during and immediately after application) (Capel et al., 2001; Holvoet et al., 2007), thus serving to emphasize contemporary pesticides in the aqueaous phase and their related effects on aquatic communities (Schaefer et al., 2011; Schaefer et al., 2012) with a focus on run-off from rain events (Wittmer et al., 2010; Wittmer et al., 2011). Importantly, recognition of sediments as an important delivery pathway for pesticide contamination is increasing (Kuivila et al., 2012; Warren et al., 2003), but studies are still lacking which include a wider range of legacy pesticides. In addition, a dearth of both chronic and sediment toxicity values has complicated a more holistic evaluation. A re-examination of the history and legacy of pesticide usage together with trends in measured pesticide concentrations in groundwater, surface water and the sediment-phase is therefore crucial to our understanding how to mitigate their impacts.

Our main objective was to couple current findings of pesticides in Danish streams and groundwater (McKnight et al., 2012; Rasmussen et al., 2013) to the history of pesticide usage, in particular focusing on whether legacy pesticides contribute to the overall predicted toxicity impacting aquatic benthic macroinvertebrates. This is driven especially by the hypothesis that an examination of only the recent pesticide application history (one decade or less) may not be sufficient to guarantee the sustainable 
management and restoration of impaired aquatic resources. This could have ramifications for our understanding of pesticide fate, pathways and resulting ecotoxicological effects. More specific objectives were to: (i) assess pesticide trends using five decades of agricultural application data, as well as stream concentrations for the pesticides found in 14 Danish headwater streams, (ii) evaluate observed stream water concentrations collected under different hydrological conditions to identify the role of the groundwater route for pesticides in streams, and (iii) identify which pesticides (contemporary; legacy) and phases (dissolved, sediment-bound) contribute to predicted ecotoxicological potential in streams.

\section{The legacy of pesticide usage}

Although the first recorded use of pesticides dates back to ca. $2500 \mathrm{BC}$ when farmers began using chemical sulfur to kill pests on crops (Unsworth, 2010), the modern-day development and application of pesticides was initiated after the Second World War. Earlier pesticidesconsisted predominantly of inorganic substances derived from natural sources containing large quantities of metals, e.g. arsenic, copper, and lead, and were heavily in use up until the 1940s (Nollet and Rathore, 2010; Uneke, 2007). Their application led to the accumulation of metals in the subsurface that could potentially re-mobilize depending on the prevailing geochemical and climatic conditions. Early organic pesticides such as nitrophenols, chlorophenols and petroleum oils were by-products of industrial processes such as coal gas production, and were used against fungal infections and insect pests (Rathore and Nollet, 2012; Unsworth, 2010). Disadvantages to the use of these substances included the high rates of application, non-specificity and resulting high (phyto-)toxicity.

In order to combat these disadvantages, the 1940s led to an accelerated growth in the development of natural (plant-based) pesticides, as well as the introduction of synthetic organic compounds with the discovery of the effects of organochlorines, such as DDT, and phenoxy acids, e.g. dichlorprop. These chemicals were effective and inexpensive, with DDT being the most popular due to its broad-spectrum activity, and were thought to consist of less dangerous substances since they appeared to be less toxic to mammals and reduced insect-borne diseases such as malaria (Unsworth, 2010). However, many of these chemicals were later found to vary in aquatic (acute) toxicity from moderately toxic (U.S. EPA category II (Kegley et al., 2008), e.g. DDT; organophosphates: chlorpyrifos) to extremely toxic (U.S. EPA category I (Kegley et al., 2008), e.g. organochlorines: lindane; dinitrophenols: dinoseb) depending 
113 on the specific properties of the substance, such as biodegradability, tendency to bioaccumulate, and

114 carcinogenicity (e.g. DDT, lindane). Many of the organochlorines have now been banned or

115 discontinued because of these traits (DG SANCO, 2014).

116 Organophosphates, triazines (e.g. atrazine), phenoxy acids (MCPA), carbamates (pirimicarb),

117 triazoles (propiconazole) and pyrethroids ( $\lambda$-cyhalothrin) have been used in contemporary pest control

118 since the 1940s. These compounds are often characterized as being more stable, albeit less persistent

119 than the organochlorines, with a mode of action that is less specific compared to the compounds

120 developed during the 1970s. Pesticides first introduced in the 1970s have been further adapted to

121 contain only organic substances without metals, must now pass more stringent controls (transport;

122 degradation; ecotoxicity), and are typically developed for a specific target (e.g. endocrine disruption,

123 electron transport inhibition); examples include isoproturon, glyphosate and metamitron. Their frequent

124 use in modern agricultural and urban areas is attributed to their exceptional pesticidal activity greatly

125 reducing application rates (Uneke, 2007). However their increased selectivity has led to increased

126 problems with resistance, leading to the need for management strategies to combat this negative effect

127 (Unsworth, 2010).

128 More recently, pesticides are being developed solely by genetic engineering. These pesticides are

129 hypothesized to be safer than previously developed compounds (Uneke, 2007), but their environmental

130 impacts are still largely unknown (e.g. as a part of the cocktail of pesticides impacting non-target

131 organisms). New pesticide chemistry utilizing traditional (eco)toxicological methods, has also allowed

132 better resistance management (in part through the implementation of integrated pest management

133 systems), improved selectivity and better environmental and toxicological profiles (Unsworth, 2010).

\section{3. Methods}

1353.1 Study catchments

136 Fourteen headwater streams in four catchments located on Sjaelland, Denmark were selected (Fig.

137 1A), and the concentrations of pesticides - including selected metabolites and impurities - were

138 determined for the dissolved and sediment-bound phases. Two of these streams were chosen as least

139 disturbed control sites, representing (sub)catchments with $>90 \%$ forested or natural lands (CS1-2; Fig.

140 1A). Eleven streams were chosen in the Hove catchment (Fig. 1B), where agriculture represents $80 \%$ of 
141 the catchment land use (Rasmussen et al., 2013). One stream is located in the Skensved catchment (Fig.

142 1C), where agriculture represents ca. 99\% of the total land use (McKnight et al., 2012).

143 Although the Hove and Skensved catchments differ in catchment size (and thus number of

144 tributaries) and degree of physical in-stream (habitat) degradation, they are similar in that the dominant

145 arable crop types are wheat, barley and canola (visual observations 2010-2012). There is no substantial

146 input from waste water treatment plants in the investigated first-order streams, but storm water run-off

147 from the scattered settlements may contribute to stream water quality (McKnight et al., 2012).

148 Discharge from contaminated sites, and in particular abandoned landfill sites, can include pesticides at

149 specific locations (Milosevic et al., 2012). All catchments are characterized by low elevations,

150 clayey/loamy soils, a temperate climate, and an average regional precipitation of $600 \mathrm{~mm} \mathrm{yr}^{-1}$ (Hansen

151 et al., 2011). Tile drains, triggered by storm-flow events and wet seasons, are present in agricultural

152 fields in both catchments.

153
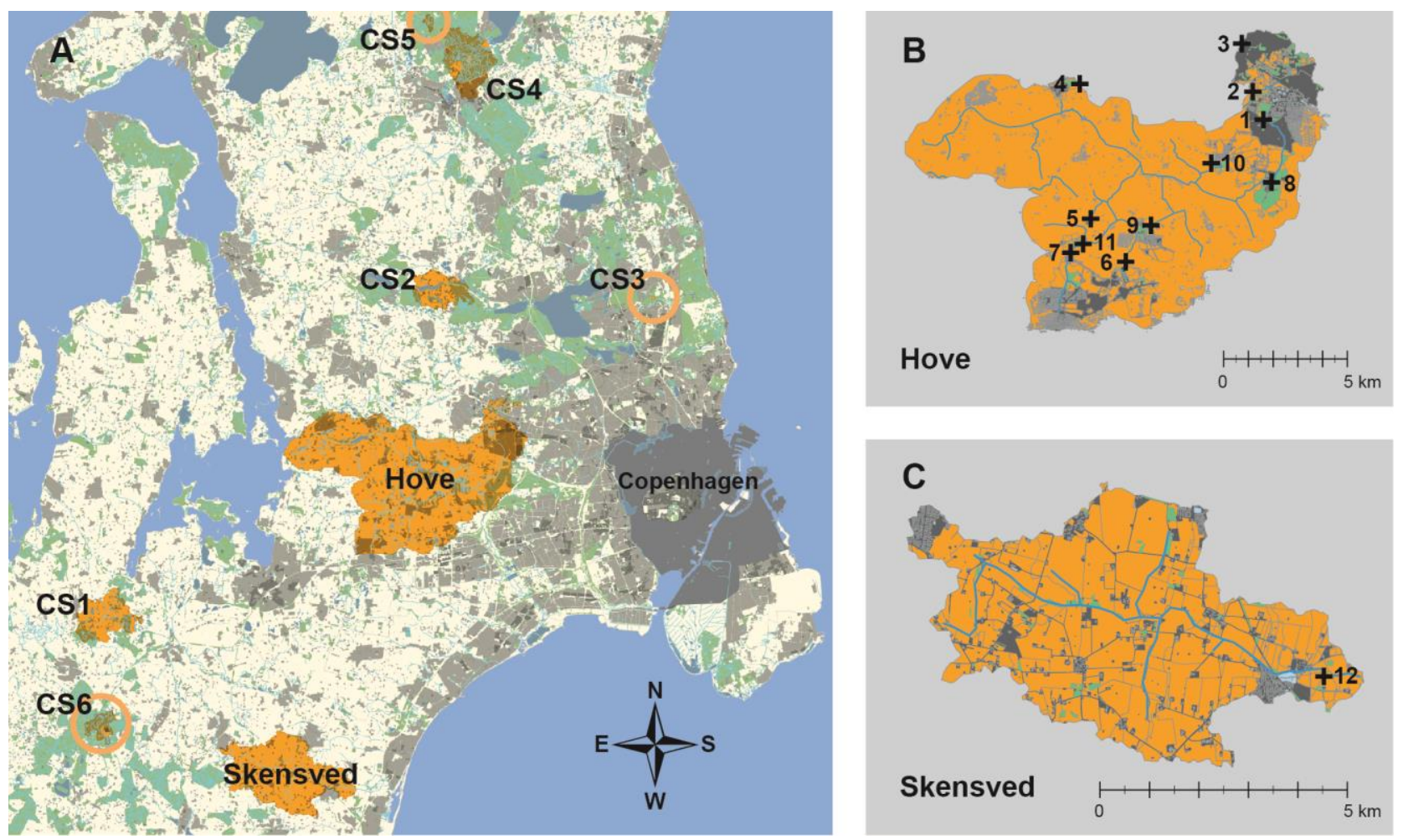

Fig. 1: Location of the study catchments (A) on Sjaelland, Denmark, including their relation to the six least disturbed control catchments (labelled CS1-6); the (B) Hove and (C) Skensved catchments together with their respective stream networks. In Fig. (a), green and gray areas indicate natural and urban areas, respectively. In Figs. (B) and (C), green, orange, 
160

161

162

163

164

165

166

167

168

169

170

171

172

173

174

175

176

177

178

179

180

181

182

183

184

185

186

187

188

sampled during this field campaign; all other control catchments was taken from the NOVANA database (Danish EPA, 2011).

\subsection{Pesticides}

The chemicals in the study were generally selected to represent the most relevant pesticides with respect to legacy (e.g. banned herbicides now commonly found in groundwater) and contemporary-use, different physicochemical properties (SI Table S1) and toxicity. We included a range of pesticides determined by evaluating the probable relationships between pesticide, crops and spraying practice (SI Tables S2-S3), and sales statistics expected to be used in the catchments during 2010-2012. Nine of the pesticides on the Danish top 15 sales list for 2010 were included (based on metric tonnes active ingredient sold; SI Table S4). We did not include glyphosate in this study because it has an extremely low aquatic toxicity (LC50 D.magna $=40 \mathrm{mgL}^{-1}$; University of Hertfordshire (2014)), so will not affect the toxicity calculations (see Section 3.4), and requires an extra analytical protocol.

\subsection{Pesticide sampling and analyses}

Sampling was conducted in May-August from 2010-2012 during the main pesticide application period in Denmark. Dissolved-phase pesticides were sampled using opaque 1-L event-triggered water samplers as described in Liess and von der Ohe (2005) during May and June to capture surface runoff and flow through tile drains during heavy precipitation events, resulting in 8 storm-flow event samples. The bottles were retrieved within $24 \mathrm{~h}$ after each precipitation event, not filtered, and stored at $4{ }^{\circ} \mathrm{C}$ until analysis by Eurofins Miljoe A/S Laboratories. One grab-sample was collected at each site in August 2010 after a period with little to no precipitation and restrictions on the application of pesticides (close to harvest), representing base-flow conditions. Sediment-bound phases aiming to capture the most lipophilic pesticides were collected using two methods: suspended sediment (typically fine particles, e.g. silts; colloidal aggregates) was collected using passive suspended particle samplers (SPS) placed in 4 selected streams during May-June 2011 (Laubel et al., 2001). The top $2-5 \mathrm{~cm}$ of (stream)bed sediment (BS) (typically coarse particles, e.g. sands; gravel) was collected manually at one site in August 2012 using Kayak corers following the method described in Kronvang et al. (2003). The sample consisted of ca. 25 sub-samples collected in depositional areas to meet minimum analytical requirements for sample mass. Further details of the study catchments, sampling methods and pesticide screening are provided elsewhere (McKnight et al., 2012; Rasmussen et al., 2013). Analysis of water 
samples for non-polar compounds were conducted using liquid-liquid extraction followed by quantification on GC-MS. Polar compounds were solid-phase extracted and quantified by liquid chromatography tandem mass spectrometry (LC-MS/MS), as described in Jansson and Krueger (2010). An overview of analytes in the different phases and sampling campaigns is presented in SI Table S5.

\subsection{Toxicity calculation}

The predicted toxicity for dissolved-phase pesticides was estimated using the toxic unit (TU) approach (Tomlin, 2001) with Daphnia magna as the benchmark organism (OECD, 2010): $T U=\mathrm{C}_{i} / L C 5 O_{i}$, where $C_{i}$ is the measured concentration of pesticide $i, L C 5 O_{i}$ the corresponding acute 48h LC50 value for D. magna exposed to pesticide $i$ (see SI Table S6 for ecotoxicity data). In the absence of ecotoxicity data for metabolites/impurities, the LC50 values were assigned the same value as the parent compounds.

We calculated the sum of all TUs ( $\left.\sum T \mathrm{TU}\right)$ in order to produce a conservative estimate for the toxicity, in line with the principle of screening-level risk assessments. For this reason, if a single substance had multiple test values, the lowest value reported was used. $\sum \mathrm{TU}$ is based on the assumption of toxic additivity, neglecting potential synergistic and antagonistic effects between chemicals. Although studies have shown that this approach can result in an overestimation of mixture toxicity, it is generally within a factor of two or three of the observed toxicity and is as such defendable as a precautionary default assumption (Faust et al., 2003; Belden et al., 2007). Moreover, Schaefer et al. (2013) showed that $\sum$ TU generally correlated as well or better than other toxicity predictions (i.e. independent action) to an ecological indicator of pesticide pollution (SPEAR) suggesting that the $\sum$ TU is a reasonable predictor for actual toxic pressure to aquatic biota. Liess and von der Ohe (2005) and Schaefer et al. (2012) have suggested $\log T U \geq-3.0$ as a threshold value for acute observed effects on the aquatic macroinvertebrate community structure in the field. However, their studies were based on

$212 \mathrm{TU}_{\max }$; thus it should be noted that our use of $\sum \mathrm{TU}$ is probably slightly more conservative. Note that 213 samples without pesticides measured at or above the detection limit were assigned a very low TU-value $214(-8.0)$.

215 The predicted toxicity of the sediment-bound pesticides was estimated using measured bulk 216 sediment concentrations of contaminants, which were converted into aqueous concentrations according 217 to the equilibrium-partitioning approach for non-ionic organic chemicals (see SI Table S1). The TU 
could then be determined in accordance with the dissolved-phase approach. This approach is in line with previous studies focusing on the partitioning, bioavailability and toxicity of pyrethroid insecticides, suggesting that equilibrium partitioning theory could be used to reasonably predict sediment toxicity (Maund et al., 2002). It should be noted that this method entails considerable uncertainty, since the compounds may not be in equilibrium in stream sediment and it is difficult to measure $\mathrm{K}_{\mathrm{oc}}$ for highly hydrophobic compounds. Direct calculation for predicted sediment toxicity was not possible due to a lack of data (e.g. using chronic 28d NOEC sediment toxicity values) for many of the detected compounds.

We calculated TU for the sediment samples using Chironomus riparius as the benchmark organism. We assembled data for three exposure scenarios: acute 96h LC50, chronic 28d NOEC (spiked water) and chronic 28d NOEC (spiked sediment) (SI Table S6). Where no data was available, we supplemented with data for other test organisms (Chironomus tentans; Chironomus dilutus (previously called $C$. tentans); Gammarus lacustris; Hyalella azteca). For the calculation of $\sum \mathrm{TU}$ for sediment samples, we prioritized data in the following order: 1) chronic 28d NOEC for Chironomus sp., 2) $96 \mathrm{~h}$ acute LC50 for Chironomus sp. and 3) chronic exposure tests for alternative species. Moreover, we assembled data for 21-d NOEC for D. magna for all compounds detected in a sediment sample. For some compounds, no values could be found (SI Table S7), and our toxicity estimates are therefore likely to underestimate the potential toxicity of the samples.

We calculated the average $\log \sum \mathrm{TU}$ for permitted pesticides and compared them to the average $\log \sum \mathrm{TU}$ for all detected pesticides $(t$-test, $\alpha=0.05)$ for base-flow, storm-flow and the sediment samples. Additionally, we compared the average $\log \sum \mathrm{TU}$ of all detected pesticides in storm-flow samples with the average $\log \sum \mathrm{TU}$ of base-flow samples $(t$-test, $\alpha=0.05)$. The tested data fulfilled the requirements for normality (Shapiro-Wilk) and equal variances (Bartlett's test; $\alpha=0.05$ ); the two sampled control sites were not included in any of the statistical analyses.

\section{Results and discussion}

\subsection{Historical use of pesticides in Denmark}

The historical agricultural use of pesticides in Denmark is presented by an overview of sales data for the active ingredients sold from 1956-2010 (Fig. 2). Specifically, we give an overview for the 32 pesticides detected in this study, with the addition of glyphosate. It can be seen that sales peaked just 
247 under 4,400 metric tonnes in 1983. In comparison, the total amount of pesticides sold during this period 248 peaked at ca. 9,200 tonnes in 1983 of which ca. 5,000 tonnes were herbicides (SI Figure S1). The 249 pesticides detected in this study thus comprise ca. $45 \%$ of the total pesticides sold. The specific 250 pesticides used have changed greatly over time. Herbicides such as trichloroacetic acid (TCA), 251 dichlorprop and MCPA dominated the sales from 1960-1970, to be substituted by compounds such as 252 glyphosate and isoproturon in the early 1980s and 1990s. Further details on the historical use trends in 253 Denmark for detected compounds are given in SI Table S2.

254 Comparing trends for agricultural land use in Denmark over three decades revealed only a slight 255 decline in the total area cultivated (from ca. 2.5 M-ha to 2.2 M-ha); thus only small changes were seen 256 in the total treatment frequency (SI Table S3) and the total number of pesticides sold (e.g. 1,168 in 257 1990; 1,153 in 2010). However, for some crop types major changes are evident, which could also 258 reflect the changing use patterns of pesticides, and changes in agricultural practice (Hansen et al., 259 2011). For example, for one of the dominant crop types in Denmark (winter cereals) and for corn, the 260 treatment frequency has been cut by over $60 \%$; whereas for potatoes, it has increased by ca. $35 \%$. 261 Herbicides, in all cases, are by far the most widely applied pesticides, followed by fungicides and 262 insecticides. 


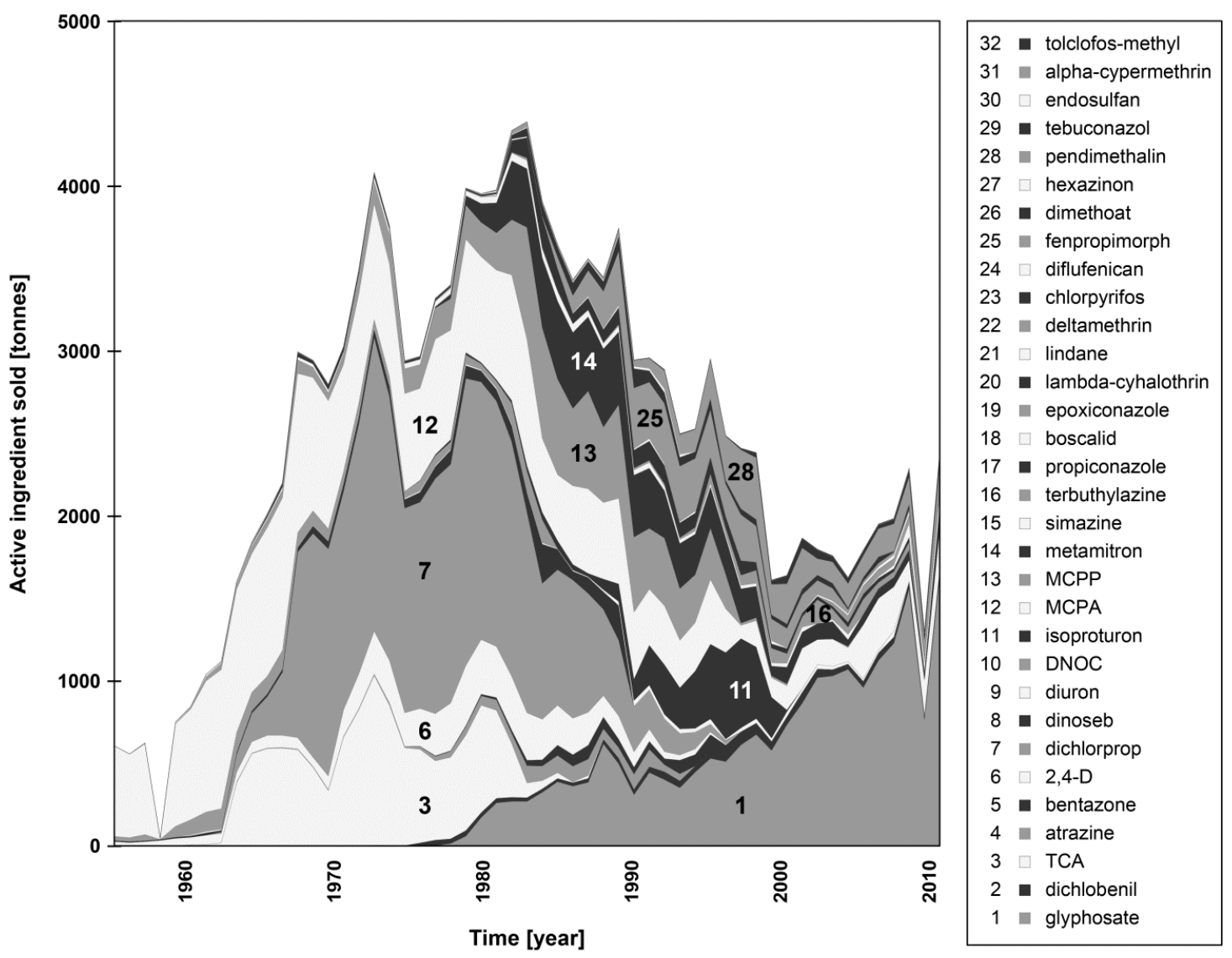

264 Fig. 2. Sales of detected active ingredients (incl. glyphosate) in Denmark for agricultural use between 1956-2010, shown as stacked shaded areas. Hexachlorobenzene is not present, as it was never authorized for use as a fungicide in Denmark. Adapted from Tuxen et al. (2013).

\subsection{Overview of current pesticide findings}

Figure 3 presents the findings for all stream site locations sampled in 2010-2012 for both the dissolved and sediment samples. In total, 32 pesticides were detected at least once and these findings are composed of 18 herbicides, 7 fungicides and 7 insecticides. In addition to hexachlorobenzene, another 9 compounds were detected comprising metabolites, intermediates, potential impurities or isomers of a pesticide (see also SI Table S8).

\subsubsection{Dissolved-phase pesticide findings}

The number of compounds found per stream site ranged from 5 to 24 for storm-flow samples, and 275 from 1 to 10 for base-flow samples (SI Table S9). SI Table S9 furthermore gives an overview of which compounds were most widespread (found in multiple streams) and in which phase, as well as which 
278 TCA (1988), simazine (2004), 2,6-dichlorobenzamide (BAM, metabolite) and MCPA (4th most sold 279 pesticide in 2010; SI Table S4) were by far the most prevalent compounds detected in the water 280 samples. Metamitron additionally belongs to this group as it was detected at 11 of the 12 agriculturally281 impacted sites, although it was detected only during one storm-flow event in 2010 (see Fig. 4).

282 Notably, 4 to 5 compounds were also detected in the control (least disturbed) sites during storm283 flow events, including BAM. BAM is a metabolite of dichlobenil, which is typically associated with 284 urban applications and not with agricultural use (Clausen et al., 2007) and is one of the most common 285 contaminants in Danish aquifers (Malaguerra et al., 2012). This finding was expected considering that 286 scattered settlements are typical of the Danish rural landscape (see Fig. 1). 

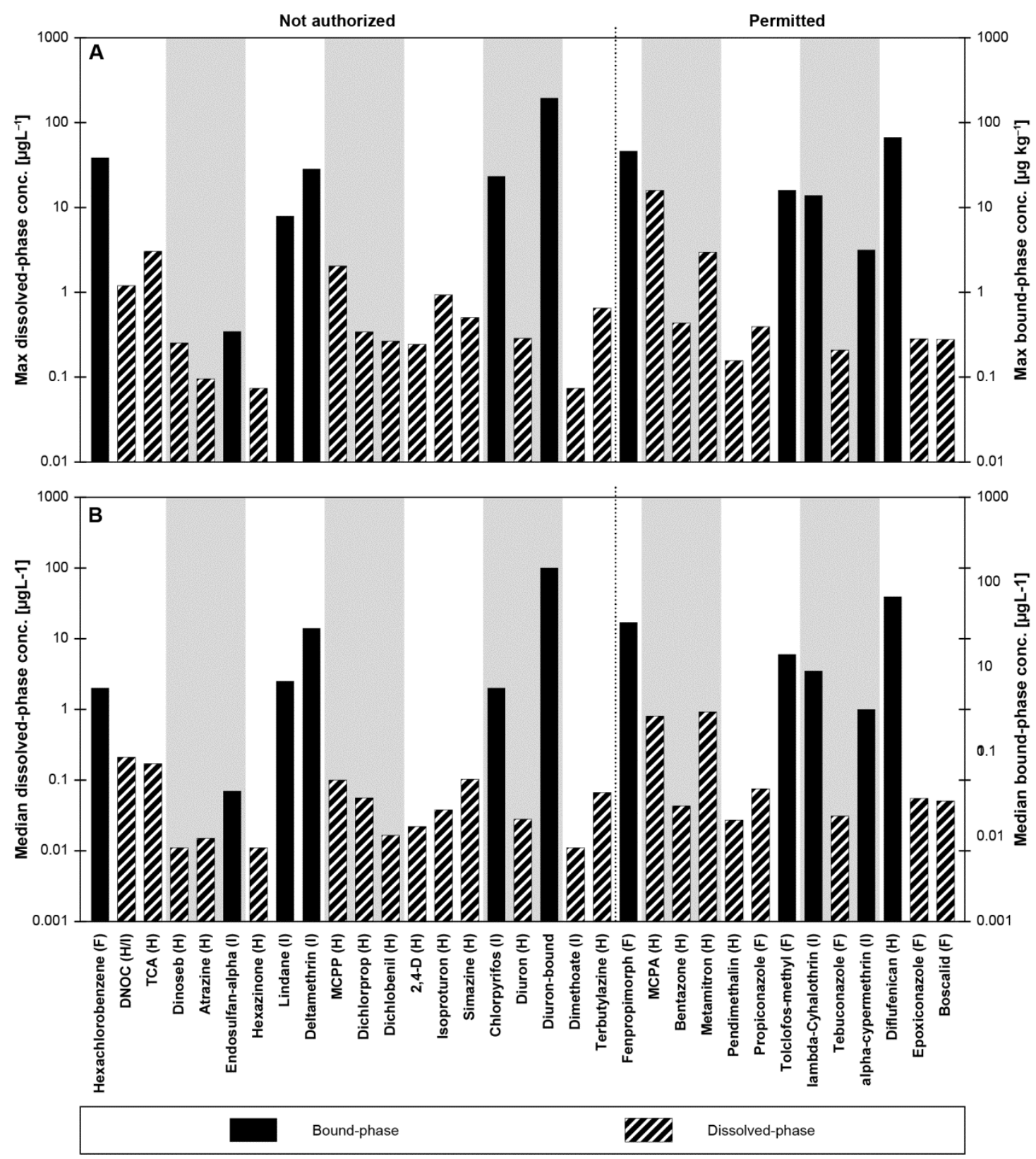

288 Fig. 3. Overview of (a) maximum and (b) median pesticide concentrations in the water (dissolved phase - striped bars) and associated with sediments (bound-phase - solid bars), for herbicides (H), insecticides (I) and fungicides (F) measured during the field campaign (excluding control sites). Note the dotted black line that marks the transition from not authorized to permitted status according to Danish legislation, although some may still be permitted within the European Union. We consider some pesticides as not being authorized when the yearly registered sales are below 4 metric tonnes (i.e. 2,4-D, MCPP), indicating these chemicals are being phased out. SI Table S8 provides an overview of the maximum concentrations and features of compounds detected in this study. SI Table S9 presents an overview of the extent of detected compounds in streams in the study area. Note that endosulfan-alpha was found above the detection limit in one bed sediment sample, but below the quantification limit: its inclusion here is to document its presence, i.e. trace concentration. 
Eleven different chemicals in total were detected in the sediment samples (Fig. 3), where hexachlorobenzene, chlorpyrifos and diflufenican were the most prevalent (SI Table S9). Six of these chemicals are no longer authorized for use in Denmark. Although four chemicals were detected in the bed sediment, only diuron was measured above the limit for quantification (SI Table S8). The total number of compounds ranged from 4 to 6 per site. For site 7-V1 (SI Table S9), where both sediment sampling methods were carried out, chlorpyrifos was additionally detected in the suspended sediment, which was not present in the streambed sample. The herbicide diuron was the only pesticide found in all the phases considered in this study (SI Table S5). Notably, many of the (lipophilic) fungicides (e.g. fenpropimorph) and insecticides (e.g. chlorpyrifos) detected in this study were only found in the sediment-phase. Findings were similar to the dissolved-phase, showing a mix of banned and contemporary pesticides.

The presence of hexachlorobenzene, never authorized for use in Denmark, could be due to the importation of products which contain it, such as biocide-treated woods, PVC, fireworks or synthetic rubber (Paludan et al., 2004). It could also be present since it is a known by- and combustion-product in the production process for chlorinated solvents and organochlorine pesticides (Gilbert, 2012; Lützhøft et al., 2012). Chlorpyrifos, banned in 2006 in Denmark but still permitted within the EU (SI Table S2),

314 is a broad-spectrum chlorinated organophosphate insecticide and biocide (e.g. incorporated in paint as a means of vector control) (Mackay et al., 2014).

\subsubsection{Priority pollutants}

317 Eight of the nine pesticides included on the European 33 priority pollutant list were detected, 318 including atrazine, chlorpyriphos, diuron, endosulfan-alpha, hexachlorobenzene, isoproturon, lindane 319 and simazine. Most of the maximum concentrations measured in the study streams fall close to the 320 reported median value for European streams (SI Table S8). The maximum detected aqueous 321 concentration for diuron and isoproturon was above or close to the EU aquatic PNEC, respectively 322 (Klein et al., 1999). The fungicide/impurity hexachlorobenzene and the insecticides lindane and endosulfan-alpha (isomer of endosulfan) were detected in the sediment at concentrations well-above 324 the EU sediment PNEC (Klein et al., 1999). Furthermore, the maximum measured concentration of 325 hexachlorobenzene was double the existing Danish freshwater guideline value of $10 \mu \mathrm{gkg}^{-1}$ (SI Table 326 S2) (Danish EPA, 2010), and it was found at all sampled locations (SI Table S9). 


\subsection{Complex picture for pesticide entry to surface water}

328 Pesticide application methods vary widely and can strongly affect how much of the applied 329 chemical reaches the target site (Vogel et al., 2008), where potentially only $0.1 \%$ of the pesticides 330 applied to crops actually reach the target pest (Arias-Estévez et al., 2008). Important factors affecting 331 the transport of pesticides within a catchment include the meteorological conditions, land use, 332 physicochemical properties and the conditions of the soil surface (Asman et al., 2005; Holvoet et al., 333 2007; Rodrigues et al., 2013). Once released, the fate of pesticides is then determined by environmental 334 processes such as volatilization (from soil and plant surfaces) and degradation (biotic and abiotic), with 335 the effect that pesticides will enter different compartments in different quantities and subsequently be 336 removed at different rates, resulting in widely varying transport distances and residence times. Here we 337 discuss the contributions and thus importance of different entry pathways for selected compounds, 338 relying on literature findings to supplement our conclusions for relevant pathways not directly 339 investigated in this study.

\subsubsection{Indications for a groundwater transport route}

341 Almost all pesticides (17 from 22 detected) not authorized for use in Denmark, and metabolites and 342 impurities, were detected during base-flow conditions when groundwater discharge is expected to be 343 the most dominant source of inflow to the streams. This is shown in Fig. 4, which separates the storm344 flow and base-flow water samples for pesticides (Fig. 4A) and detected metabolites/impurities (Fig. 345 4B). Our main criteria for inferring groundwater as a relevant pathway for specific compounds is that 346 (i) we find it under base-flow conditions in similar concentrations, if not higher, to storm-flow values 347 (see Table 1), (ii) we find them in groundwater, and (iii) maximum storm-flow and base-flow 348 concentrations were detected at the same sampling location (i.e. stream), as is discussed further below. 

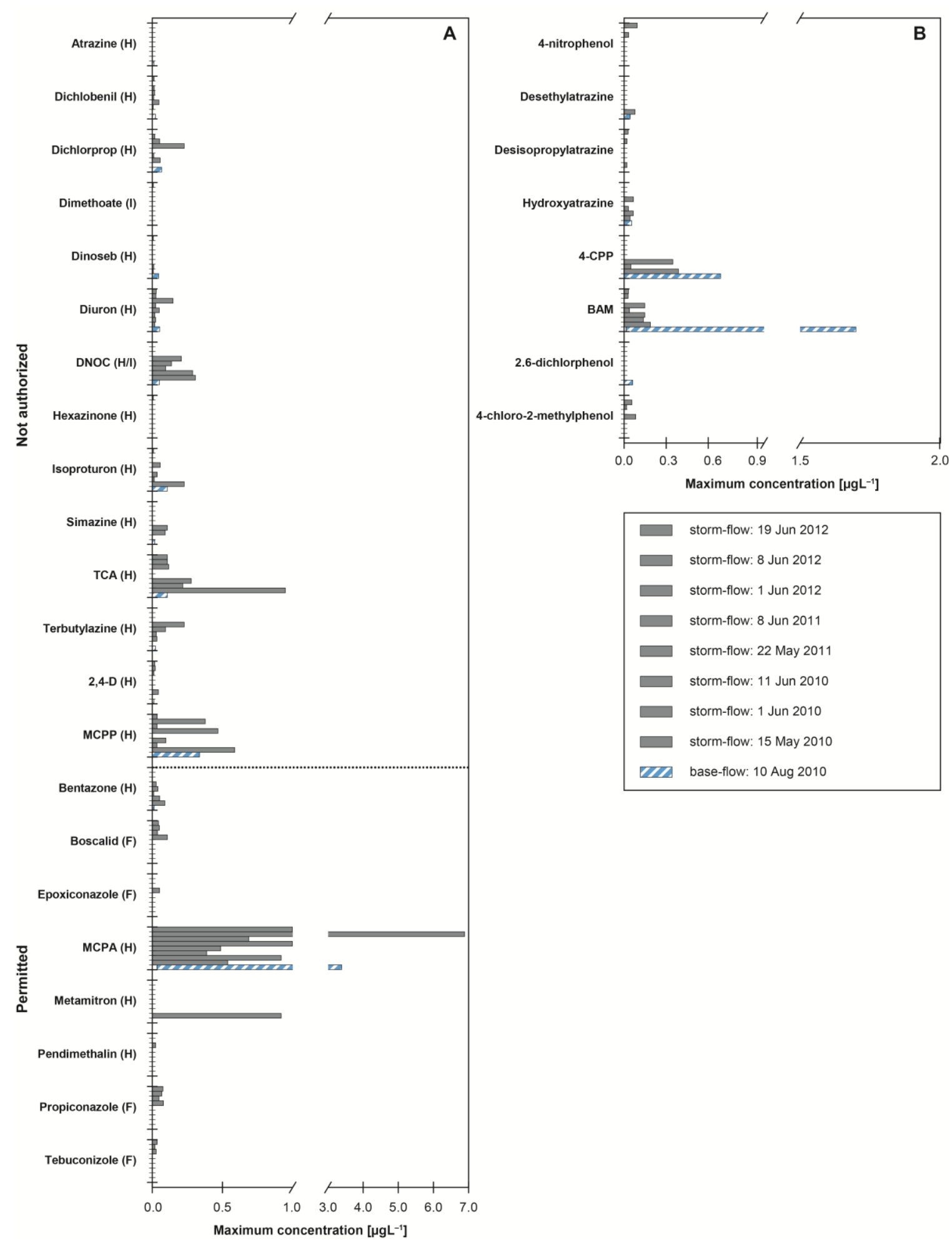

350 Fig. 4. Overview of dissolved-phase (a) pesticides and (b) metabolites and/or impurities, identified either during the base351 flow event (blue-striped bars) or during a storm-flow event (gray-scale bars). Note the dotted black line that marks the 352 transition from not authorized to permitted status according to Danish legislation. 
We can make the strongest case for BAM, dichlobenil, mecoprop (MCPP). 2(4chlorophenoxy)propionic acid (4-CPP), and MCPA. For BAM, the highest detected concentration was in the groundwater, with comparable concentrations in the base-flow (Table 1). BAM is highly soluble and non-volatile (University of Hertfordshire, 2014), in contrast to its parent compound dichlobenil (SI Table S1), so that its presence in groundwater is expected. Dichlobenil was found in lower concentrations in groundwater (Table 1), compared to its metabolite BAM (by one order of magnitude, Table 1), and was detected in higher but similar concentrations during storm-flow events compared to base-flow. This could be due to the fact that dichlobenil is typically found in the upper few meters of soil (Clausen et al., 2007) from where it could be released during heavy rain events.

The detected concentrations for MCPP in storm- and base-flow were comparable to concentrations detected in groundwater wells for the Hove catchment (Table 1, see also SI Table S10). Although the storm-flow concentrations were highest for MCPP, these values were close to the value for base-flow. In the case of MCPP, this could indicate that, although we have classified it as not authorized, MCPP-P is still in "restricted" use, although the amounts are low (below 4 metric tonnes, SI Fig. S1, SI Table $\mathrm{S} 1)$. MCPP is highly soluble and nonvolatile, further supporting this pathway as being relevant in explaining its presence in the investigated streams.

A similar case can be made for 4-CPP (metabolite/impurity of dichlorprop), although it was only detected in one groundwater well in the survey (SI Table S10). However, it was found in a later study in at least one monitoring or drinking water well close to a stream in the Hove catchment (Levi et al., 2014). In addition, a parallel study conducted at one of the Hove stream locations (8-Ri) confirmed the existence of groundwater discharge zones entering the stream. Specifically, phenoxy acid herbicides (MCPP, dichlorprop, 4-CPP) were detected in groundwater impacted by landfill leachate which enters the stream particularly during dry periods, i.e. when stream concentrations reached groundwater concentration levels (Milosevic et al., 2012).

MCPA, representing decades of both contemporary and historical use, was found at the highest concentration of all detected pesticides in water samples. Interestingly, base-flow concentrations for the restricted-use herbicide MCPA were only ca. 50\% lower than the storm-flow concentrations at the same locations (e.g. maximum detected: $6.9 \mu \mathrm{gL}^{-1}$ and $3.4 \mu \mathrm{gL}^{-1}$, respectively, for 7-V1), indicating the high importance of groundwater inflow for this compound in addition to the inflow via surface run-off and tile drains during storm-flow events. This pattern was also seen for three of the other compounds, 
383 i.e. maximum storm-flow and base-flow concentrations were found at the same location for 4-CPP (8$384 \mathrm{Ri}), \mathrm{BAM}(5-\mathrm{In})$ and dichlobenil (7-V1), suggesting that groundwater is an important contributor for 385 these compounds based on our criteria.

386 A lesser case can still be made, however, for bentazone, as well as for atrazine, 2,4-D and its 387 metabolite 2,6-dichlorophenol and isoproturon (but see also Section 4.3.2). Bentazone and 2,4-D are 388 highly soluble, compared with isoproturon (moderately soluble) and atrazine (low solubility); all of 389 these compounds are non-volatile with a low persistence in soils (DT50s) except for atrazine 390 (moderately persistant) (SI Table S1). For bentazone, although the highest concentration was detected 391 in a storm-flow event, concentrations were in the same order of magnitude for both base-flow and 392 groundwater (Table 1), which indicates that groundwater is most likely contributing to the presence of 393 bentazone in streams. For 2,4-D, the highest concentration detected was in groundwater (Table 1) with 394 similar concentrations detected in base-flow and storm-flow (same order of magnitude). The case for 395 isoproturon is similar to 2,4-D, with similar concentrations detected in base-flow and storm-flow (same order of magnitude), which could indicate that groundwater is contributing to this compound's presence in the investigated streams. In the case of atrazine, its highest concentration was detected in groundwater followed by base-flow; it was not detected in storm-flow events, which could be due to the fact that its use has been discontinued since 1994 in Denmark.

Table 1: Overview for maximum and median pesticide concentrations, including metabolites/impurities (right-justified), detected in the storm-flow, base-flow and groundwater (Hove catchment only). Note that median equals maximum for baseflow, since this was only sampled once. The maximum concentration detected per pathway is highlighted in bold.

\begin{tabular}{|c|c|c|c|c|c|}
\hline \multirow{2}{*}{ Compound } & \multicolumn{3}{|c|}{$\begin{array}{c}\text { Maximum conc. detected per compound } \\
{\left[\mu \mathbf{g L}^{-1}\right]}\end{array}$} & \multicolumn{2}{c|}{$\begin{array}{c}\text { Median conc. detected per } \\
\text { compound }\left[\boldsymbol{\mu g L} \mathbf{L}^{-1}\right]\end{array}$} \\
\cline { 2 - 6 } & Storm-flow & Base-flow & Groundwater & Storm-flow & Groundwater \\
\hline DNOC (H) & $\mathbf{0 . 3 1}$ & 0.054 & 0.10 & 0.21 & 0.01 \\
\hline TCA (H) & $\mathbf{0 . 9 5}$ & 0.11 & 0.01 & 0.17 & 0.01 \\
\hline Dinoseb (H) & 0.013 & 0.048 & $\mathbf{0 . 1 0}$ & 0.011 & 0.01 \\
\hline 4-nitrophenol & $\mathbf{0 . 0 9 6}$ & n.d. & n.d. & 0.066 & n.d. \\
\hline Atrazine (H) & n.d. & 0.015 & $\mathbf{0 . 1 0}$ & n.d. & 0.01 \\
\hline Desethylatrazine & 0.081 & 0.046 & $\mathbf{0 . 1 0}$ & 0.081 & 0.01 \\
\hline Desisoproylatrazine & 0.032 & n.d. & $\mathbf{0 . 1 0}$ & 0.023 & 0.01 \\
\hline
\end{tabular}




\begin{tabular}{|c|c|c|c|c|c|}
\hline Hydroxyatrazine & 0.069 & 0.057 & 0.10 & 0.057 & 0.01 \\
\hline Hexazinone $(\mathrm{H})$ & 0.011 & n.d. & n.d. & 0.011 & n.d. \\
\hline $\operatorname{MCPP}(\mathrm{H})$ & 0.59 & 0.34 & 0.12 & 0.10 & 0.01 \\
\hline Dichlorprop (H) & 0.23 & 0.069 & 0.06 & 0.056 & 0.018 \\
\hline 4-CPP & 0.39 & 0.69 & 0.011 & 0.35 & $\begin{array}{c}\text { only } 1 \text { finding } \\
\text { above DL }\end{array}$ \\
\hline Dichlobenil (H) & 0.051 & 0.025 & 0.02 & 0.017 & 0.01 \\
\hline BAM & 0.19 & 1.7 & 2.1 & 0.14 & 0.036 \\
\hline $2,4-\mathrm{D}(\mathrm{H})$ & 0.046 & 0.014 & 0.1 & 0.022 & 0.01 \\
\hline 2,6-dichlorophenol & n.d. & 0.064 & n.d. & n.d. & n.d. \\
\hline Isoproturon $(\mathrm{H})$ & 0.23 & 0.11 & 0.029 & 0.038 & 0.029 \\
\hline Simazine $(\mathrm{H})$ & 0.11 & 0.02 & 0.04 & 0.1 & 0.02 \\
\hline Diuron $(\mathrm{H})$ & 0.15 & 0.056 & 0.026 & 0.028 & 0.01 \\
\hline Dimethoate (I) & 0.011 & n.d. & n.d. & 0.011 & n.d. \\
\hline Terbutylazine $(\mathrm{H})$ & 0.23 & 0.026 & 0.015 & 0.067 & 0.01 \\
\hline MCPA (H) & 6.9 & 3.4 & 0.012 & 0.81 & 0.012 \\
\hline 4-chlor-2-methylphenol & 0.085 & n.d. & 0.10 & 0.058 & 0.05 \\
\hline Bentazone $(\mathrm{H})$ & 0.092 & 0.016 & 0.023 & 0.043 & 0.018 \\
\hline Metamitron $(\mathrm{H})$ & 0.92 & n.d. & 0.02 & 0.33 & 0.01 \\
\hline Pendimethaline $(\mathrm{H})$ & 0.027 & n.d. & n.d. & 0.027 & n.d. \\
\hline Propiconazole $(\mathrm{F})$ & 0.082 & n.d. & n.d. & 0.075 & n.d. \\
\hline Tebuconizole (F) & 0.038 & n.d. & n.d. & 0.031 & n.d. \\
\hline Epoxiconazole $(\mathrm{F})$ & 0.055 & n.d. & n.d. & 0.055 & n.d. \\
\hline Boscalid (F) & 0.11 & n.d. & n.d. & 0.051 & n.d. \\
\hline
\end{tabular}

\subsubsection{Indications for an atmospheric transport route}

TCA and DNOC have been banned in Denmark since 1988 and 1987, respectively (SI Table S2), and they are not found above the detection limit in groundwater in the Hove catchment (SI Table S10). 
407 Moreover, maximum storm-flow and base-flow concentrations were found at different locations, e.g. 408 TCA (3-Kr/storm-flow; 11-V2/base-flow), DNOC (3-Kr/storm-flow; 9-Bi/base-flow) or metamitron 409 (3-Kr/storm-flow; not detected in base-flow), so the groundwater pathway is considered less likely. 410 TCA is highly water soluble (SI Table S1) and has been linked to both wet and dry deposition from the 411 atmosphere, although sources and fate for this compound are still not completely understood (Cape et 412 al., 2006). Asman et al. (2005) found in a Danish study that the overall wet deposition of nitrophenols 413 (e.g. DNOC, 4-nitrophenol) were much higher than that for pesticides. Nitrophenols comprise a group 414 of compounds that are emitted by cars, but can also be formed in the atmosphere by the photochemical 415 reaction of nitrogen oxides with hydrocarbons (Asman et al., 2005) indicating that DNOC could also be 416 transported via the atmospheric pathway.

417 Metamitron was found in 11 of the 12 agricultural streams (i.e. Hove; Skensved) during one storm418 event measurement. Metamitron is a pre- and post-emergence herbicide used for weed control in sugar 419 beet and strawberry fields (SI Table S2). Strawberry fields are indeed found scattered throughout the 420 area, but are not among the dominant crop type for these catchments and these crops were not observed 421 directly bordering the sampling locations. Potentially it is transported via the atmosphere, e.g. via wind 422 drift from nearby fields. This conjecture is supported by previous studies in Danish catchments on 423 Sjaelland, which showed statistically significant losses of metamitron due to primary (droplet) and 424 secondary drift (evaporation) (Carlsen et al., 2006a; Carlsen et al., 2006b).

425 Chlorpyrifos, well-known for its persistence and ability to undergo long-range transport (Mackay et 426 al., 2014), was detected in all four suspended sediment samples, but not in the streambed sediment. 427 Although it is still permitted within the EU, it has been banned for use as an insecticide in Denmark 428 since 2006 (SI Table S2), but may still be found in material protection products, e.g. paint as a biocide. 429 Nearby scattered settlements (Fig. 1) could therefore act as sources emitting chlorpyrifos via storm430 flow runoff to streams. In addition, the atmosphere is also a likely transport pathway; chlorpyrifos was 431 among the 10 most frequently detected compounds in rainwater in four agricultural watersheds in the 432 United States (Vogel et al., 2008).

433 Several of the legacy herbicides for which there is weaker evidence for the groundwater pathway 434 (Section 4.3.1) could come in part from the atmosphere, but could also then partly have leached into 435 groundwater and from there entered the stream water. In particular, atrazine, its metabolites, 436 isoproturon, and 2,4-D were detected in rainwater in the study by Asman et al. (2005). In our study, 
437 these compounds were detected in the highest concentrations in either base-flow or groundwater, lending support to the importance of groundwater as a contributor of these compounds to stream water.

However, further work is still needed to properly disentangle the relevance of the different sources and their contribution to the presence of pesticides in surface water. This includes a closer look at the influence of biocides applied in urban settings, since it is probable that some compounds which are no longer permitted for agricultural use may still be allowed in biocides (e.g. diuron, mecoprop, Wittmer et al., 2010, see also Section 4.2.2). Specifically, a much higher temporal and spatial resolution of all sampling sites for each of these potential sources (e.g. base-flow, storm-flow, groundwater, precipitation) is essential, preferably also extending the dataset to include more catchments (e.g. mixed land use for e.g. presence of biocides) in order to support a more statistical evaluation of the data.

\subsection{Contribution of banned pesticides to predicted ecotoxicity}

448 The $\log \sum \mathrm{TU}_{\text {D.magna }}$ for permitted pesticides is depicted as a function of the $\log \sum \mathrm{TU}_{\text {D.magna }}$ for all compounds for each sample in Fig. 5. For the storm-flow samples, the addition of banned compounds significantly increased the $\log \sum \mathrm{TU}_{\text {D.magna }}$ by up to one order of magnitude $(\mathrm{P}=0.014$, Table 2$)$. Stormflow samples generally exhibited a higher $\log \sum \mathrm{TU}_{\text {D.magna }}$ compared to base-flow $(\mathrm{P}<0.001)$. The higher $\log \sum \mathrm{TU}_{\text {D.magna }}$ in storm-flow samples compared to base-flow samples was due in part to the herbicide metamitron and in part to several fungicides (see SI Table S9). These compounds have low-tomoderate toxicity to D. magna, similar to many of the herbicides detected in the base-flow samples (SI Table S6). The general increase in $\log \sum \mathrm{TU}_{\text {D.magna }}$ of storm-flow samples was therefore due primarily to the presence of higher concentrations of compounds with similar toxicity (not more toxic compounds).

For the base-flow samples, the addition of banned compounds significantly increased the $\log \sum \mathrm{TU}_{\text {D.magna }}$ by up to four orders of magnitude $(\mathrm{P}<0.001$, Table 2$)$. Importantly, contaminated groundwater inflow constitutes a chronic source of pollution, and given the relatively short time span in which standard toxicity tests are conducted, the estimated toxicity of these compounds may be underestimated. Studies using longer exposure durations are needed to fully comprehend the 462 ecotoxicological potential of groundwater-based pollution in streams. Importantly, these findings show

463 that non-authorized substances, including metabolites and impurities increase the $\log \sum \mathrm{TU}_{\text {D.magna }}$ of water samples irrespective of the entry pathway. 
Using TU based on $48 \mathrm{~h}$ acute toxicity tests with D. magna, all suspended sediment samples (SPS) were characterized by a $\log \sum \mathrm{TU}_{\text {D.magna }} \geq-3.0$ (converted to water concentrations) when all compounds were included (Fig. 5). In contrast, only two of the four SPS samples exceeded a $\log \sum \mathrm{TU}_{\text {D.magna }}$ of -3 when considering only permitted compounds. Macroinvertebrate community changes have been observed at $\log \mathrm{TU}_{\text {D.magna }}$ of -3 (Liess \& von der Ohe, 2005; Schaefer et al., 2012), and this low threshold for observed effects has been proposed to be due in part to concomitantly acting 472 environmental stressors and indirect pesticide effects facilitated through community interactions (Liess 473 $\&$ von der Ohe, 2005). Our results suggest that one possible explanatory factor governing this low 474 threshold for observed community effects in the field could be due to chronic exposure of legacy 475 pesticides especially via sediments.

For the bed sediment sample (Site 7-V1, Table 2), the predicted toxicity value is similar to the more 477 toxic storm-flow samples, remaining just below the threshold regardless of the inclusion of e.g. legacy 478 pesticides. Higher $\log \sum \mathrm{TU}_{\text {D.magna }}$ in suspended sediment compared to the bed sediment sample is probably due to the fact that the bed sediment sample was comprised of the top $2-5 \mathrm{~cm}$ in depositional zones. Given that particle-associated pesticides are likely to be primarily associated with the upper few millimeters of newly deposited sediment, the volume of deeper sediment may dilute the pesticide concentrations compared to SPS sampling (Liess et al., 1996). The $\log \sum \mathrm{TU}_{\text {D.magna }}$ for all compounds 483 detected in the sediment-phase (both suspended and bed sediment) was higher, but not statistically 484 different $(\mathrm{P}=0.055)$, than the $\log \sum \mathrm{T} \mathrm{U}_{D \text {.magna }}$ when only contemporary pesticides are included. The lack 485 of a statistically significant difference was most likely due to the small sample size. The $\log \sum \mathrm{TU}$ for 486 487 suspended and bed sediment samples were generally higher compared to the $\log \sum \mathrm{TU}$ of water samples, and the influence of banned pesticides on $\log \sum \mathrm{TU}$ appeared to increase (SI Fig. S2). 


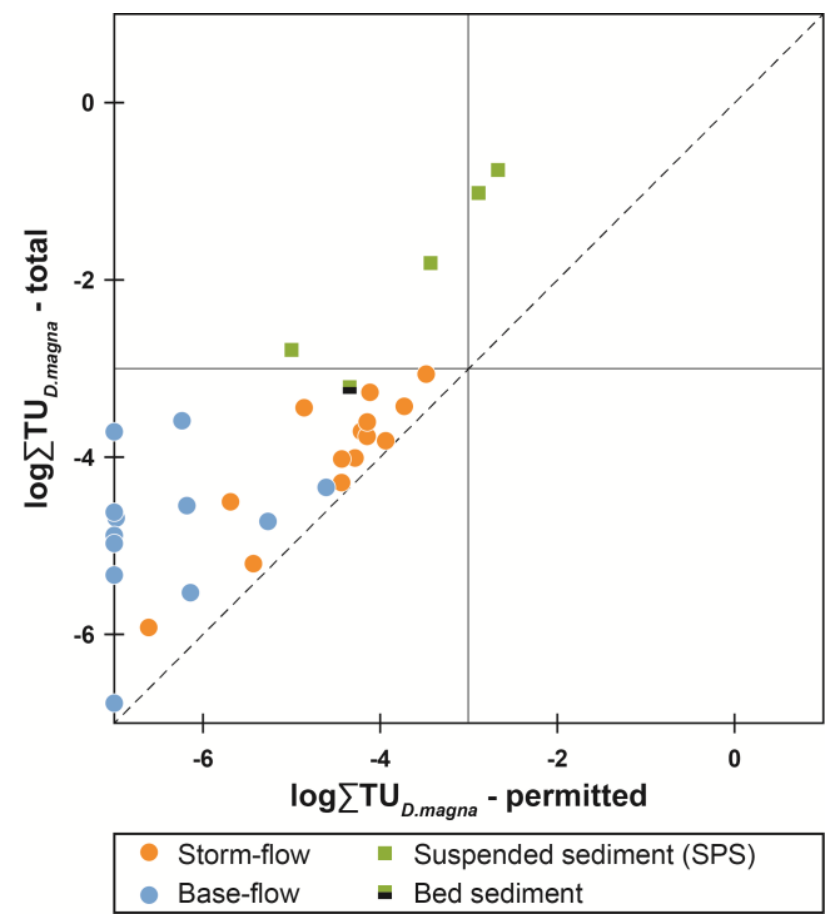

Fig. 5. $\log \sum \mathrm{TU}_{\text {D.magna }}$ for all pesticides detected, compared with the $\log \sum \mathrm{T} \mathrm{U}_{\text {D.magna }}$ considering only the currently permitted pesticides in Denmark for all pathways analyzed. Solid lines indicate the threshold for acute observed effects on macroinvertebrate community structure in the field $(\log \mathrm{TU} \geq-3.0)$ (Schaefer et al., 2012); dotted line shows 1:1 ratio.

Our findings, supported also by other published studies (Kuivila et al., 2012; Warren et al., 2003), indicate that sediment-bound pesticide residues could be important for both acute and chronic exposures of the biota since they consistently harbored high toxic potential. However, both the suspended and bed sediment samples were analyzed for a broader spectrum of insecticides that was not included in the aqueous samples. Aqueous samples could therefore have a higher toxic potential to $D$. magna than our results indicate. We furthermore suggest that future research should address chronic exposure of pesticides that have been adsorbed to particles for several months or even years to evaluate whether the predicted toxicity of the sediment-associated pesticides, in particular for the legacy pesticides, detected in agricultural streams is valid. Moreover, we emphasize the need to further develop our knowledge of the temporal dynamics in particular of legacy pesticide concentrations in stream sediments.

Table 2: $\log \sum \mathrm{TU}_{\text {D.magna }}$ for all 14 streams based on water samples collected during base-flow, storm flow or in the toxicity is very close to $(n=1)$ or exceeds $(n=7)$ the threshold $(\log T U \geq-3.0)$ for observed effects on macroinvertebrate community structure. $\mathrm{N} / \mathrm{A}=$ not analyzed, indicating streams where pathways were not sampled for a particular phase (i.e. 


\begin{tabular}{|c|c|c|c|c|c|c|c|c|c|c|c|c|c|c|}
\hline \multirow{2}{*}{$\begin{array}{l}\text { Sampling } \\
\text { pathways }\end{array}$} & \multicolumn{14}{|c|}{$\log \sum \mathrm{TU}_{\text {D.magna }}$} \\
\hline & $1-\mathrm{Ra}$ & $2-\mathrm{Ba}$ & $3-\mathrm{Kr}$ & 4-El & 5 -In & $6-\mathrm{Se}$ & $7-\mathrm{V} 1$ & $8-\mathrm{Ri}$ & 9-Bi & $10-\mathrm{O}$ & $11-\mathrm{V} 2$ & $12-\mathrm{Sk}$ & $13-\mathrm{R}$ & 14-Fa \\
\hline $\begin{array}{l}\text { Base-flow: } \\
\text { permitted }\end{array}$ & -6.14 & -6.98 & -8 & -8 & -8 & -8 & -4.61 & -6.18 & -8 & -8 & -5.27 & -6.24 & N/A & N/A \\
\hline $\begin{array}{l}\text { Base-flow: } \\
\text { total }\end{array}$ & -5.53 & -4.69 & -3.72 & -6.78 & -4.89 & -4.62 & -4.34 & -4.55 & -5.33 & -4.98 & -4.73 & -3.59 & N/A & N/A \\
\hline $\begin{array}{l}\text { Storm-flow: } \\
\text { permitted }\end{array}$ & -5.69 & -4.86 & -3.73 & -4.43 & -4.21 & -4.11 & -3.48 & -4.28 & -4.43 & -3.94 & -4.15 & -4.14 & -6.61 & -5.43 \\
\hline $\begin{array}{l}\text { Storm-flow: } \\
\text { total }\end{array}$ & -4.51 & -3.44 & -3.43 & -4.29 & -3.71 & -3.27 & -3.07 & -4.01 & -4.02 & -3.82 & -3.77 & -3.61 & -5.93 & -5.20 \\
\hline $\begin{array}{l}\text { Sediment } \\
\text { (SPS): } \\
\text { permitted }\end{array}$ & N/A & N/A & -2.67 & N/A & N/A & -5.00 & -3.43 & N/A & N/A & N/A & N/A & -2.89 & N/A & N/A \\
\hline $\begin{array}{l}\text { Sediment } \\
(\mathrm{SPS}): \text { total }\end{array}$ & N/A & N/A & -0.76 & N/A & N/A & -2.79 & -1.81 & N/A & N/A & N/A & N/A & -1.02 & N/A & N/A \\
\hline $\begin{array}{l}\text { Bed sediment: } \\
\text { permitted }\end{array}$ & N/A & N/A & N/A & N/A & N/A & N/A & -4.35 & N/A & N/A & N/A & N/A & N/A & N/A & N/A \\
\hline $\begin{array}{l}\text { Bed sediment: } \\
\text { total }\end{array}$ & N/A & N/A & N/A & N/A & N/A & N/A & -3.21 & N/A & N/A & N/A & N/A & N/A & N/A & N/A \\
\hline
\end{tabular}

\section{Implications of pesticide findings in streams}

\subsection{Historical versus contemporary use}

511 Our study investigates both the occurrence and pathways for pesticides in stream water. The results

512 provide a snapshot of the pesticides found in Danish streams, recording only presence/absence of a

513 small percentage of the total number of chemicals that have been, or currently are on the market. These

514 findings contribute to a more holistic understanding of stressors potentially impacting freshwater

515 ecosystems, revealing the presence of legacy pesticides in different media to which aquatic organisms

516 are exposed.

517 Pesticide concentrations in surface water bodies are consistent with trends in current agricultural

518 use (Thurman et al., 1992; Vecchia et al., 2009), particularly for run-off associated with rain events,

519 when only contemporary pesticides are included in the sampling campaign. However, studies of

520 pesticides in groundwater present similar conclusions to our work, with concentrations being related to 
521 the time when these compounds were first introduced (Tesoriero et al., 2007). Here we have clearly 522 documented the presence of pesticides that have, in some cases, been removed from the Danish and/or

523 European market for over several decades. Notably, predicted toxicity increased by up to four orders of 524 magnitude when detected legacy pesticides, and their metabolites and impurities, were included in the 525 calculation.

526 A closer look at the top 15 pesticides sold over the last decade in Denmark indicates that these 527 accounted for ca. $63 \%$ of all pesticides sold in Denmark in 2000 (or ca. $75 \%$ of all herbicides), rising to 528 ca. $90 \%$ in 2010 (ca. 93\% of all herbicides; SI Table S4). Seven out of the 9 analyzed pesticides from 529 this group were detected in this study. Notably, there were no insecticides among these 7 compounds; 530 in fact, boric acid was the top insecticide sold (in 2010, but since banned in the EU), placing 21st 531 overall, with cypermethrin - detected in this study - placing $25^{\text {th }}$ (Tuxen et al., 2013). This information 532 is relevant to our findings, where both historical and contemporary insecticides were only rarely 533 detected in the dissolved-phase, but consistently in the sediment-phase, which also exhibits the highest 534 predicted toxicity. Herbicides dominate the total sales, are more mobile and thus more likely to be 535 found in groundwater (SI Table S10). The higher concentrations of herbicides observed in our samples 536 are likely related to the higher use of herbicides in agriculture, noting that we did not analyze for or 537 detect many insecticides or fungicides in the dissolved-phase (SI Table S5). This is due to the fact that 538 insecticides and fungicides found around detection limits in the solid phase will not allow 539 quantification in the water phase due to their highly lipophilic nature. Groundwater is thus likely to 540 continue to be an important pathway in particular for herbicides in surface water for decades to come.

\subsection{Considerations for determining toxicity}

542 Although our study presents only predicted chemical toxicity findings, which alone can only 543 support the possibility that chemical stressors may have contributed to impacts on aquatic ecosystems, 544 we speculate that the role of chronic exposure of pesticides from groundwater and sediments are 545 currently underestimated (Bundschuh et al., 2014; Peters et al., 2013). We were surprised to discover a 546 huge paucity of data for chronic sediment toxicity values for benthic macroinvertebrates. Although 547 there are reasons for this, i.e. non-standardized methods, this is important considering the number of 548 compounds detected in the sediment-phase in our study. Indeed, current risk assessment methods 549 based on no-observed-adverse-effect-levels for single chemicals - do not provide sufficient information 
550 about the effects of chronic exposure - over macroinvertebrate generations (Artigas et al., 2012) - to

551 low-concentration mixtures punctuated by seasonal high-concentration pulses (Gilliom et al., 1999).

552 They also do not consider the adjuvants pesticides are sold in - i.e. only active ingredients are tested for 553 ecotoxicity, as the adjuvant is thought to be inert (Benachour and Seralini, 2009) - representing

554 potential important gaps in our knowledge of the impacts of pesticides on aquatic ecosystems.

\subsection{Considerations for monitoring programs for streams and groundwater}

Our findings indicate that monitoring programs comprised only of current trends in agricultural pesticide use (one decade or less), will not be representative of what actually exists in streams and groundwater. The principle of 'you find what you look for' is certainly valid here, as assumptions about the fate and transport of pesticides, including dominant sources and entry pathways, must clearly be reevaluated. We suggest that legacy pesticides and their metabolites/impurities should be included in monitoring programs if the 'true' toxic effect of pesticides in streams is to be assessed.

The importance of the groundwater pathway for headwater streams indicates that stream sampling during base-flow conditions can provide valuable information about the long-term fate of pesticides in groundwater. Both aqueous and sediment phases should be sampled to assess the health of streams and rivers. Ideally, integrative approaches should be developed with monitoring strategies simultaneously involving chemical analyses, ecotoxicological tools and the study of population/community responses

567 (Connon et al., 2012) in order to obtain a more holistic picture.

\section{Conclusions}

This study aimed to link the history of pesticide usage to current findings for legacy and contemporary pesticides in surface and groundwater. We investigated, in particular, how legacy pesticides contribute to the ecotoxicological impact on stream water ecosystems. Findings comprised a 572 range of both banned legacy and contemporary pesticides in 14 Danish headwater streams.

573 Groundwater has been identified as a significant pathway especially for herbicides entering streams, 574 and should be assessed together with input from atmospheric sources and run-off from rain events to 575 get the full picture of stream water quality. Legacy pesticides contribute to predicted aquatic ecotoxicity, which was increased substantially (up to four orders of magnitude) when these pesticides, and their metabolites and impurities, were included in the toxicity estimations. 
Sediment-bound insecticides, such as chlorpyrifos and deltamethrin, were a major source for the estimated ecotoxicity. Their presence could be due either to long-range transport in the atmosphere or to storm-flow run-off to streams from e.g. urban applications such as biocides. Our results corroborate other published studies indicating that sediment-bound pesticide residues could be important for both acute and chronic exposures of the biota. We suggest, however, that chronic toxicity scenarios are potentially more representative of the overall conditions found in streams, demonstrating the importance of the lack of long-term chronic exposure data in the literature. Thus monitoring programs comprised only of current trends in agricultural pesticide use (i.e. one decade or less), will not be representative of actual conditions in streams. Legacy pesticides and their metabolites and/or impurities should therefore be included in stream water monitoring programs in order to provide a "true" assessment of pesticide impact on streams.

\section{Acknowledgements}

This work was supported by the Danish Strategic Research Council (RiskPoint project). We thank all persons involved in the field studies analyzed in this paper. We additionally thank two anonymous reviewers for their valuable comments and suggestions for improving the clarity of this paper.

\section{Supporting information}

Figures for sales trends of selected pesticides and for the evaluation of different exposure durations on the toxicity calculation. Tables of the physicochemical properties of the detected compounds, an overview of their use and legal status, trends of treated areas/frequencies, top-15 Danish pesticide usage statistics, overview of analytes and sampling campaigns, acute/chronic toxicity data, the number of compounds for which additional exposure data exists, an overview of the pesticides detected in this study including EU norms, an overview of the impacted streams, pesticide detection results in groundwater extraction wells, and for an extended overview of the predicted toxicity for sedimentbound pesticides. 
603

604

605

606

607

608

609

610

611

612

613

614

615

616

617

618

619

620

621

622

623

624

625

626

627

628

629

630

631

632

633

634

635

636

637

638

639

640

641

642

643

644

645

\section{References}

Arias-Estévez, M.; López-Periago, E.; Martínez-Carballo, E.; Simal-Gándara, J.; Mejuto, J.-C.; GarcíaRío, L. The mobility and degradation of pesticides in soils and the pollution of groundwater resources. Agriculture, Ecosystems \& Environment 2008;123:247-260.

Artigas, J.; Arts, G.; Babut, M.; Caracciolo, A.B.; Charles, S.; Chaumot, A.; Combourieu, B.; Dahllöf, I.; Despréaux, D.; Ferrari, B.; Friberg, N.; Garric, J.; Geffard, O.; Gourlay-Francé, C.; Hein, M.; Hjorth, M.; Krauss, M.; De Lange, H.J.; Lahr, J.; Lehtonen, K.K.; Lettieri, T.; Liess, M.; Lofts, S.; Mayer, P.; Morin, S.; Paschke, A.; Svendsen, C.; Usseglio-Polatera, P.; van den Brink, N.; Vindimian, E.; Williams, R. Towards a renewed research agenda in ecotoxicology. Environmental Pollution 2012;160:201-206.

Asman, W.A.H.; Jorgensen, A.; Bossi, R.; Vejrup, K.V.; Mogensen, B.M.; Glasius, M. Wet deposition of pesticides and nitrophenols at two sites in Denmark: measurements and contributions from regional sources. Chemosphere 2005;59:1023-1031.

Barth, J.A.C.; Steidle, D.; Kuntz, D.; Gocht, T.; Mouvet, C.; von Tümpling, W.; Lobe, I.; Langenhoff, A.; Albrechtsen, H.J.; Janniche, G.S.; Morasch, B.; Hunkeler, D.; Grathwohl, P. Deposition, persistence and turnover of pollutants: First results from the EU project AquaTerra for selected river basins and aquifers. Science of The Total Environment 2007;376:40-50.

Beketov, M.; Kefford, B.J.; Schaefer, R.B.; Liess, M. Pesticides reduce regional biodiversity of stream invertebrates. Proceedings of the National Academy of Sciences 2013;110(27):11039-11043.

Belden, J.B.; Gilliom, R.J.; Martin, J.D.; Ludy, M.J. Relative toxicity and occurrence patterns of pesticide mixtures in streams draining agricultural watersheds dominated by corn and soybean production. Integrated Environmental Assessment and Management 2007;3:90-100.

Benachour, N.; Seralini, G.E. Glyphosate Formulations Induce Apoptosis and Necrosis in Human Umbilical, Embryonic, and Placental Cells. Chemical Research in Toxicology 2009;22:97-105.

Bundschuh, M.; Goedkoop, W.; Kreuger, J. Evaluation of pesticide monitoring strategies in agricultural streams based on the toxic-unit concept - Experiences from long-term measurements. Science of The Total Environment 2014;484:84-91.

Cape, J.N.; Forczek, S.T.; Gullner, G.; Mena-Benitez, G.; Schroder, P.; Matucha, M. Progress in understanding the sources, deposition and above-ground fate of trichloroacetic acid. Environmental Science and Pollution Research 2006;13:276-286.

Capel, P.D.; Larsen, S.J.; Winterstein, T.A. The behavior of thirty-nine pesticides in surface waters as a function of scale. Hydrological Processes 2001;15:1251-1269.

Carlsen, S.C.K.; Spliid, N.H.; Svensmark, B. Drift of 10 herbicides after tractor spray application. 1. Secondary drift (evaporation). Chemosphere 2006a;64:787-794.

Carlsen, S.C.K.; Spliid, N.H.; Svensmark, B. Drift of 10 herbicides after tractor spray application. 2. Primary drift (droplet drift). Chemosphere 2006b;64:778-786.

Clausen, L.; Arildskov, N.P.; Larsen, F.; Albrechtsen, H.-J. Degradation of the herbicide dichlobenil and its metabolite BAM in soils and subsurface sediments. Journal of Contaminant Hydrology 2007;89:157-173.

Connon, R.E.; Geist, J.; Werner, I. Effect-Based Tools for Monitoring and Predicting the Exotoxicological Effects of Chemicals in the Aquatic Environment. Sensors 2012;12:1274112771. 
Danish EPA. NOVANA: Det nationale program for overvågning af vandmiljøet og naturen. Programbeskrivelse 1. del. ISBN: 978-87-7279-101-7. Miljøministeriet, Naturstyrelsen: Copenhagen, DK; 1-22; 2011 [in Danish].

Danish EPA. Bekendtgørelse om miljøkvalitetskrav for vandområder og krav til udledning af forurenende stoffer til vandløb, søer eller havet. Miljøministeriet: Copenhagen, DK; 1-18; 2010 [in Danish].

Danish EPA. Bekaempelsesmiddelstatistik 2010, Orientering fra Miljoestyreslsen Nr. 5. Miljoeministeriet, Miljoestyreslsen: Copenhagen, DK; 1-48; 2011 [in Danish]. DG SANCO. EU Pesticides Database. [Online] http://ec.europa.eu/sanco_pesticides/public/; 2014. Ejrnaes, R.; Baatrup-Pedersen, A.; Riis, T.; Pedersen, M.L.; Hoffmann, C.C.; Kronvang, B., Johansen, O.M. Herbicider i terrestriske vådområder: Herbiciders forekomst, mængde, spredningsveje og effecter i moser i udvalgte jyske ådale. Bekæmpelsmiddelforskning nr. 154; ISBN: 978-8793178-09-0. Miljoeministeriet, Miljoestyreslsen: Copenhagen, DK; 1-122; 2014. [in Danish].

Faust, M., Altenburger, R., Backhaus, T., Blanck, H., Boedeker, W., Gramatica, P., Hamer, V., Scholze, M., Vighi, M., Grimme, L.H. Joint algal toxicity of 16 dissimilarly acting chemicals is predictable by the concept of independent action. Aquatic Toxicology 2003;63:43-63.

Fenner, K.; Canonica, S.; Wackett, L.P.; Elsner, M. Evaluating Pesticide Degradation in the Environment: Blind Spots and Emerging Opportunities. Science 2013;341:752-758.

Gilbert, S.G.A Small Dose of Toxicology: The Health Effects of Common Chemicals. Seattle: Healthy World Press; 2012.

Gilliom, R.J. Pesticides in U.S. streams and groundwater. Environmental Science \& Technology 2007;41:3407-3413.

Gilliom, R.J.; Barbash, J.E.; Kolpin, D.W.; Larson, S.J. Testing water quality for pesticide pollution. Environmental Science \& Technology 1999;33:164A-169A.

Hansen, B.; Thorling, L.; Dalgaard, T.; Erlandsen, M. Trend Reversal of Nitrate in Danish Groundwater - a Reflection of Agricultural Practices and Nitrogen Surpluses since 1950. Environmental Science \& Technology 2011;45:228-234.

Holt, E.; Weber, R.; Stevenson, G.; Gaus, C. Polychlorinated Dibenzo-p-Dioxins and Dibenzofurans (PCDD/Fs) Impurities in Pesticides: A Neglected Source of Contemporary Relevance. Environmental Science \& Technology 2010;44:5409-5415.

Holvoet, K.M.A.; Seuntjens, P.; Vanrolleghem, P.A. Monitoring and modeling pesticide fate in surface waters at the catchment scale. Ecological Modelling 2007;209:53-64.

Jansson, C.; Kreuger, J. Multiresidue Analysis of 95 Pesticides at Low Nanogram/Liter Levels in Surface Waters Using Online Preconcentration and High Performance Liquid Chromatography/Tandem Mass Spectrometry. Journal of AOAC International 2010;93:17321747.

Kegley, S.E., Hill, B.R., Orme, S., Choi, A.H. PAN pesticide database. North America, San Francisco, CA: Pesticide Action Network; 2008

Klein, W.; Denzer, S.; Herrchen, M.; Lepper, P.; Müller, M.; Sehrt, R.; Storm, A.; Volmer, J. Revised Proposal for a List of Priority Substances in the Context of the Water Framework Directive (COMMPS Procedure): Final Report 98/788/3040/DEB/E1. Schmallenberg, Germany: Fraunhofer-Institute, Umweltchemie und Ökotoxikologie; 1999.

Kolpin, D.W., Thurman, E.M., Linhart, S.M. Occurrence of cyanazine compounds in groundwater: Degradates more prevalent than the parent compound. Environmental Science \& Technology 2001;35:1217-1222. 
Konstantinou, I.K.; Hela, D.G.; Albanis, T.A. The status of pesticide pollution in surface waters (rivers and lakes) of Greece. Part I. Review on occurrence and levels. Environmental Pollution 2006;141:555-570.

Kronvang, B.; Laubel, A.; Larsen, S.E.; Friberg, N. Pesticides and heavy metals in Danish streambed sediment. Hydrobiologia 2003;494:93-101.

Kuivila, K.M.; Hladik, M.L.; Ingersoll, C.G.; Kemble, N.E.; Moran, P.W.; Calhoun, D.L.; Nowell, L.H.; Gilliom, R.J. Occurrence and Potential Sources of Pyrethroid Insecticides in Stream Sediments from Seven U.S. Metropolitan Areas. Environmental Science \& Technology 2012;46:4297-4303.

Laubel, A.; Kronvang, B.; Fjordback, C. Time-integrated suspended sediment sampling from a small lowland stream. Vereinigung für theoretische und angewandte Limnologie 2001;28:1420-1424.

Levi, S.; Hybel, A.M.; Bjerg, P.L.; Albrechtsen, H.J. Stimulation of aerobic degradation of bentazone, mecoprop and dichlorprop by oxygen addition to aquifer sediment. Science of The Total Environment 2014;473-474:667-675.

Liess, M.; Schulz, R.; Neumann, M. A method for monitoring pesticides bound to suspended particles in small streams. Chemosphere 1996;32:1963-1969.

Liess, M.; von der Ohe, P.C. Analyzing effects of pesticides on invertebrate communities in streams. Environmental Toxicology and Chemistry 2005;24:954-965.

Lützhøft, H.C.H.; Donner, E.E.; Wickman, T.T.; Eriksson, E.E.; Banovec, P.P.; Mikkelsen, P.S.; Ledin, A.A. A source classification framework supporting pollutant source mapping, pollutant release prediction, transport and load forecasting, and source control planning for urban environments. Environ Sci Pollut Res Int 2012;19:1119-1130.

Lyandres, O, Keeping Great Lakes Water Safe: Priorities for Protecting against Emerging Chemical Pollutants. Ed. Campbell, S., [Online] http://www.greatlakes.org/document.doc?id=1263. Chicago, IL: Alliance for the Great Lakes; 2012.

Mackay, D.; Giesy, J.P.; Solomon, K.R. Fate in the environment and long-range atmospheric transport of the organophosphorus insecticide, chlorpyrifos and its oxon. Reviews of Environmental Contamination and Toxicology 2014;231:35-76.

Malaguerra, F.; Albrechtsen, H.-J.; Thorling, L.; Binning, P.J. Pesticides in water supply wells in Zealand, Denmark: A statistical analysis. Science of The Total Environment 2012;414:433-444.

Maund, S.J.; Hamer, M.J.; Lane, M.C.G.; Farrelly, E.; Rapley, J.H.; Goggin, U.M.; Gentle, W.E. Partitioning, bioavailability, and toxicity of the pyrethroid insecticide cypermethrin in sediments. Environmental Toxicology and Chemistry 2002;21:9-15.

McKnight, U.S.; Rasmussen, J.J.; Kronvang, B.; Bjerg, P.L.; Binning, P.J. Integrated assessment of the impact of chemical stressors on surface water ecosystems. Science of The Total Environment 2012;427-428:319-331.

Milosevic, N.; Thomsen, N.I.; Juhler, R.K.; Albrechtsen, H.J.; Bjerg, P.L. Identification of discharge zones and quantification of contaminant mass discharges into a local stream from a landfill in a heterogeneous geologic setting. Journal of Hydrology 2012;446-447:13-23.

Nollet, L.M.L.; Rathore, H.S.Handbook of Pesticides: Methods of Pesticide Residues Analysis. Boca Raton, FL: CRC Press, Taylor and Francis Group, LLC; 2010.

OECD. OECD Guidelines for the Testing of Chemicals: Sediment-Water Chironomid Life-Cycle Toxicity Test Using Spiked Water or Spiked Sediment. Section 2: Effects on Biotic Systems, Test No. 233. ISBN: 9789264090910; DOI: 10.1787/9789264090910-en. 1-29; 2010. 
Olsen, P.; Ernsten, V.; Jacobsen, O.H.; Hansen, N.; de Jonge, L.W.; Kjær, J. Transport modes and pathways of the strongly sorbing pesticides glyphosate and pendimethalin through structured drained soils. Chemosphere 2011;84:471-479.

Paludan, E.; Borling, P.; Poulsen, J. 22 hormonforstyrrende aktivstofferkortlaegning over anvendelse i andre produkter end plantebeskyttelsesmidler. Miljoeprojekt Nr. 933 2004; Danish EPA; 2004 [in Danish].

Peters, K.; Bundschuh, M.; Schaefer, R.B. Review on the effects of toxicants on freshwater ecosystem functions. Environmental Pollution 2013;180:324-329.

Rasmussen, J.J.; McKnight, U.S.; Loinaz, M.C.; Thomsen, N.I.; Olsson, M.E.; Bjerg, P.L.; Binning, P.J.; Kronvang, B. A catchment scale evaluation of multiple stressor effects in headwater streams. Science of The Total Environment 2013;442:420-431.

Rathore, H.S.; Nollet, L.M.L.Pesticides: Evaluation of Environmental Pollution. Boca Raton, FL: CRC Press, Taylor and Francis Group, LLC; 2012.

Reitzel, L.A.; Tuxen, N.; Ledin, A.; Bjerg, P.L. Can degradation products be used as documentation for natural attenuation of phenoxy acids in groundwater? Environmental Science \& Technology 2004;38:457-467.

Rodrigues, E.T.; Lopes, I.; Pardal, M.A. Occurrence, fate and effects of azoxystrobin in aquatic ecosystems: A review. Environment International 2013;53:18-28.

Roy, J.W.; Bickerton, G. Toxic Groundwater Contaminants: An Overlooked Contributor to Urban Stream Syndrome? Environmental Science \& Technology 2012;46:729-736.

Schaefer, R.B.; Gerner, N.; Kefford, B.J.; Rasmussen, J.J.; Beketov, M.A.; de Zwart, D.; Liess, M.; von der Ohe, P.C. How to Characterize Chemical Exposure to Predict Ecologic Effects on Aquatic Communities? Environmental Science \& Technology 2013;47:7996-8004.

Schaefer, R.B.; von der Ohe, P.C.; Kuehne, R.; Schueuermann, G.; Liess, M. Occurrence and Toxicity of 331 Organic Pollutants in Large Rivers of North Germany over a Decade (1994 to 2004). Environmental Science \& Technology 2011;45:6167-6174.

Schaefer, R.B.; von der Ohe, P.C.; Rasmussen, J.; Kefford, B.J.; Beketov, M.A.; Schulz, R.; Liess, M. Thresholds for the Effects of Pesticides on Invertebrate Communities and Leaf Breakdown in Stream Ecosystems. Environmental Science \& Technology 2012;46:5134-5142.

Schwarzenbach, R.P.; Escher, B.I.; Fenner, K.; Hofstetter, T.B.; Johnson, C.A.; von Gunten, U.; Wehrli, B. The challenge of micropollutants in aquatic systems. Science 2006;313:1072-1079.

Squillace, P.J.; Thurman, E.M.; Furlong, E.T. (1993). Groundwater as a nonpoint-source of atrazine and deethylatrazine in a river during base-flow conditions. Water Resources Research 1993;29:1719-1729.

Stokstad, E.; Grullon, G. Infographic: Pesticide Planet. A global look at the uses, benefits, and drawbacks of pesticides. Science 2013;341:730-731.

Tesoriero, A.J.; Saad, D.A.; Burow, K.R.; Frick, E.A.; Puckett, L.J.; Barbash, J.E. Linking groundwater age and chemistry data along flow paths: Implications for trends and transformations of nitrate and pesticides. Journal of Contaminant Hydrology 2007;94:139-155.

Thurman, E.M.; Goolsby, D.A.; Meyer, M.T.; Mills, M.S.; Pomes, M.L.; Kolpin, D.W. A reconnaissance study of herbicides and their metabolites in surface-water of the midwestern United States using immunoassay and gas-chromatography mass-spectrometry. Environmental Science \& Technology 1992;26:2440-2447.

Tomlin, C.D.S.The pesticide manual, a world compendium. Farnham, Surrey, UK: Crop Protection Publications; 2001. 
Tuxen, N.; Roost, S.; Kofoed, J.L.L.; Aisopou, A.; Binning, P.J.; Chambon, J.; Bjerg, P.L.; Thorling, L.; Bruesch, W.; Esbensen, K. Skelnen mellem pesticidkilder. Miljoeprojekt nr. 1502; Miljoeministeriet, Miljoestyrelsen: Copenhagen, DK; 2013 [in Danish].

Uneke, C.J.Integrated Pest Management for Developing Countries: A Systemic Overivew. New York: Nova Science Publishers, Inc.; 2007.

University of Hertfordshire. The Pesticides Properties DataBase (PPDB). 2014. [Online] http://sitem.herts.ac.uk/aeru/iupac/. International Union of Pure and Applied Chemistry, Agriculture \& Environment Research Unit, School of Life Sciences, University of Hertfordshire: Hatfield, Herts., UK.

Unsworth, J. History of Pesticide Use. 2010. IUPAC International Union of Pure and Applied Chemistry; June 24, 2014, [Online] http://agrochemicals.iupac.org/index.php?option=com_sobi2\&sobi2Task=sobi2Details\&catid= 3\&sobi2Id=31.

Vecchia, A.V.; Gilliom, R.J.; Sullivan, D.J.; Lorenz, D.L.; Martin, J.D. Trends in Concentrations and Use of Agricultural Herbicides for Corn Belt Rivers, 1996-2006. Environmental Science \& Technology 2009;43:9096-9102.

Vogel, J.R.; Majewski, M.S.; Capel, P.D. Pesticides in rain in four agricultural watersheds in the United States. Journal of Environmental Quality 2008;37:1101-1115.

Warren, N.; Allan, I.J.; Carter, J.E.; House, W.A.; Parker, A. Pesticides and other micro-organic contaminants in freshwater sedimentary environments - a review. Applied Geochemistry 2003;18:159-194.

Wittmer, I.K.; Bader, H.P.; Scheidegger, R.; Singer, H.; Lück, A.; Hanke, I.; Carlsson, C.; Stamm, C. Significance of urban and agricultural land use for biocide and pesticide dynamics in surface waters. Water Research 2010;44:2850-2862.

Wittmer, I.K.; Scheidegger, R.; Bader, H.-P.; Singer, H.; Stamm, C. Loss rates of urban biocides can exceed those of agricultural pesticides. Science of The Total Environment 2011;409:920-932. 